given 3 grains of aspirin. According to Dr. Cohen it has no place in the treatment of acute infections. In comparatively small doses, it is useful in chronic painful affections. As to the action of the salicylates in general, he said, the salicyl ion, in whatever form it may be introduced, appears to be a chemical antitoxin. The phenomena of acute articular rheumatism in so far as they are capable of relief by salicyl compounds will be relieved before intoxication with the drug occurs. Its administration should stop when there appears the first evidence of so-called physiologic action. It must stop absolutely for the time and not be repeated until the tinnitus has disappeared.

Some persons can bear hardly one grain and some can take enormous doses. Dr. Cohen has rarely exceeded 90 grains in 24 hours. He prefers sodium salicylate above all the preparations of salicylic acid. The true or natural salt should ulways be specified, as the synthetic preparations contain irritant by-products and gastric disturbance is, as a rule, owing to t.lese, rather than to sodium salicylate itself. When the patient is weak or subject to recurrences, the addition of iron to the salicylic treatment is highly useful, and may be accomplished by the pharmaceutical expedient set forth in Dr. Cohen's paper. In regard to the tonsil and the throat, he emphasized again that not only the mouth and the throat and the faucial region, but also the nose and postpharyngeal region must be looked into and treated effectively. It is probable that some varicties of the ordinarily harmless flora of these regions become pathogenic under favoring conditions in susceptible individuals.

\section{HEMICRANIOSIS AND CURE OF BRAIN TUMOR BY OPERATION.*}

WILLIAM G. SPILLER, M.D.

r'rofessor of Neuropathology and Associate Professor of Neurology in the University of Pennsylvania. FIILLADELPHIA.

Under the name of hemicraniose Brissaud and Lereboullet ${ }^{1}$ describe a condition observed by them in two cases-a hypertrophy localized exclusively to a half of the cranium including the face. The first patient had epileptic convulsions. The enlargement of the head was first noticed about the age of two months, and it was slowly progressive and without pain. The patient had no headache, although he complained of a sense of heaviness in the head. His vision was good. He had no vomiting. The interesting feature of the case was the frontoparietal exostosis. The prominence did not extend into the occipital region nor beyond the median line.' There was also a supraorbital enlargement of bone, but the rest of the face was not affected. This was purely a clinical case.

The second patient, a woman, had cranial hemihypertrophy dating from childhood, also signs of brain tumor, the latter of two and a half years' duration. She had also exophthalmos. The hemihypertrophy was rightsided, slight in the superior and inferior maxillary bones, more pronounced in the frontal bone, and enormous in the frontoparietal region. The slope of the prominence extended to the other side of the cranium, so that the enlargement was not strictly confined to onehalf of the skull. It was hard and painless. The ne'ropsy showed that the entire inner portion of the right side of the dura was covered with tumors of different

* Read in the Section on Nerrous and Mental Diseases of the American Medical Association, at the lifity-eighth Annual Session, lield at Atlantic City, June, 1907.

* From the Lepartment of Neurology and the Laboratory of Serropathology in the Lniversity of Pennsylyania.

1. Revue Neurol., June 15, 1903, p. 537. sizes (angiolithic sarcomata). The largest of these had made a depression for itself in the brain. 'The inner left side of the cranium was not abnormal, but on the right side of the calvarium the dura was adherent in places, the bone was irregular, and tumors were found within the dura.

In both these cases there was frontoparictal and supraorbital hyperostosis, and in one a slight implication of the facc. All the tumors that were found in the second case had their origin in the dura. The authors suppose that the dura which in youth as internal periosteum had contributed to the progressive development of the hyperostosis, after the period of growth was passed, had its activity directed in another way, causing neoplastic proliferation. The unilaterality in both cases was absolute, they say, but the picture they present of the second patient shows very clearly that the slope of the prominence on the top of the head passed beyond the median line. The picture is the reverse of the hemiatrophy of the face of Romberg confined to the distribution of the fifth nerve. The hemicraniosis seems to be almost limited to the distribution of the ophthalmic branch. The dura is supposed by its outer surface to cause proliferation of the bone, and by its inner surface. the formation of tumors. Although no operation was performed nor necropsy obtained in the first case, the convulsions suggested the possibility of intracranial tumor.

Parhon and Goldstein have reported a case of hemicraniosis in a woman whose only signs of intracranial discase were hemiplegia and mental depression. An exostosis the size of a walnut was in the right parictal region. When the skull was opened the bony tumor wis found to protrude on the inner side of the skull, and it had caused a depression in a tumor of the dura beneath it. The tumor was the size of a small orange and in. volved the greater part of the motor zone and a part $n f^{\circ}$ the frontal lobe. It was circumscribed and distinct from the brain. The dura over it was adherent to the cranium. The calvarium was in general thicker on the side of the tumor. The microscopic examination showed that the new growth was a psammoma or angiolithic sarcoma. The bony tumor was very compact and hard. The authors did not notice carefully whether any hyperostosis was present in the supraorbital and frontoparictal regions. Parhon believed a relation of cause and effect cxisted between the tumor of the bone and that of the brain, and Babès thinks there is no doubt of this, as the consistency showed that the bony tumor must be vory old, and that it probably caused the psammoma by the constant irritation of the meninges. Babès, in discussing the case at a mecting, spoke of its importance, as it was the first time he had seen a tumor of one nature give origin to another of an entirely different nature. The case of Brissaud and Lereboullet and that of Parhon and Goldstein are the only cases of hemicraniosis with anatomopathologic examination in the literature, Parhon and Nadjede ${ }^{2}$ assert, and these authors add a third case.

Their patient, a woman aged 63 ycars, had apoplexy and remained left hemiplegic, but the clinical history is very incomplete. At the necropsy the dura was found adherent to the anterior part of the calvarium, and in this area a bony prominence was detected the size of a nut in the middie and posterior part of the right frontal bone. There was no enlargement on the externar surface

2. Revue Neurol., Nov. 15, 1905, p. 1017. 
of the skull. A tumor the size of the half of a small orange was found growing from the dura over the prefrontal lobe beneath the bony prominence. Microscopic examination showed that the growth was an angiolithic sareoma or psammoma.

The authors confess ignorance concerning the etiology of this condition, why the proliferation of the cranium should occur, and especially in its anterior portion, as a result of the activity of the external portion of the dura, and why from the activity of its inner portion origin is given to psammomata. In the case of Brissaud and Lereboullet there were multiple tumors, but in the other two cases the tumors were solitary.

Whether this hemicraniosis is essentially different from exostosis of the upper part of the cranium, such as is described in the recent paper of von Eiselsberg, ${ }^{3}$ is, I think, open to question.

A case of endothelioma invading the skull, not unlike my first case, has recently been reported by Barling and Leith. ${ }^{4}$ The bone over the center of the tumor in the brain for an area of about three-quarters of an inch was slightly thickened. Apparently hemicraniosis was rot perceptible in this case. Endothelioma growing from the dura and deeply indenting the brain may exist, howcver, without causing thickening of the skull, and I have such a specimen in my collection.

In reporting two cases of hemicraniosis I may call attention to the fact that the notes of my first case were $\mathrm{r}$ ad at a society meeting in $1899,{ }^{5}$ but the proceedings of this society are not published.

In both my cases the enlargement was on the left side, and in one case was strictly unilateral and in the other almost confined to one side, although it implicated the other side of the cranium to about the same extent as did the enlargement in the second case reported by Brissaud and Lereboullet. In both my cases an endothelioma was found growing from the dura and pushing the brain before it. In both opcration was attempted, but in the first case the bone of the cranium was so implicated by the tumor, and hemorrhage on this account was so profuse that all attempt to removê the tumor had to be abandoned. The disappearance of nearly every symptom after the first operation when the skull was opened in the second case was the result of decompression, and relief was obtained for several months. I think it a fortunate thing that the dura was not incised at the first operation, as the tumor would then have been discovered and its removal attempted. The time given to the patient for complete recovery after the first operation made him more vigorous to endure a second, and the tumor was removed later with comparatively little danger to the patient. The cranium in my second case was very dense, but was not infiltrated by tumor; had it been, as in the first case, the result of operation wonld have been grave.

Disappearance of all symptoms after removal of a brain tumor is exceedingly rare. The most euccessful case in my own experience previous to the one I now report was that of a parietal tumor reported by Dr. C. K. Mills; Dr. W. W. Keen and myself. This patient $I$ saw in consultation with Dr. Mills a number of times, and improvement lasted about four years after the removal of the tumor, but recurrence then occurred and a second operation proved fatal. The hemiplegia in this patient never disappeared entirely.

$\therefore$ Arcive für klin. Chirurgle, vol, 18xxl, p. 1.

4. Iancet, Aug, 4. 1906 . p. 242 .

$\therefore$ The Section on General Medicine of the College of Pbysicians of jiviladelphia.
In one of the cases ${ }^{6} \mathrm{I}$ now report almost every symptom disappeared since the second operation. 'The patient's speech is very nearly or fully normal, if he does not talk too rapidly; he has no hemiplegia, no optic neuritis, no disturbance of writing, little or no paresthesia of the hand, little or no abnormality of gait, and no exaggeration of the patellar reflexes.

In a recent discussion on cerebral and spinal tumors Trause ${ }^{7}$ remarked that true recovery from brain tumor after operation is always very rare Schultze reported that in 19 operations performed on 97 cercbral tumors only once recovery occurred, lasting a few years after the operation, and the case was one of cerebellar tumor. Oppenheim has had 27 cases of tumor of the brain with operation since 1903 . Of these 3 were with cure, 6 with temporary improvement, 15 with fatal termination. Bruns says he has never had entirely satisfactory results in operation on brain tumors, and von Monakow has had only one successful case, and in this the tumor was in the motor region. Horsler, at the meeting of the British Medical Association in Toronto, in 1906, exhibited the photographs of a patient from whom a cerehellar tumor had been very successfully remored some timé ago.

A case of brain tumor with disappearance of the symptoms after operation has been reported by Oppenheim and Krause. ${ }^{8}$ The patient had right hemihypossthesia, hemiataxiä, hemiparesis, hemianopsia and hearlache. A tumor was removed from the occipital lobe. Two months later the patient had merely some difficulty in reading and the visual field of the right eye was a little contracted.

A still more brilliant case of cure of brain tumor by opcration is one described by Oppenheim and Borchardt, ${ }^{9}$ in which a tumor the size of an egg was removed from the cerebello-pontile angle. The symptoms, which were very grave, gradually disappeared after the operation, and eight months later the patient could be pronounced cured.

In both my cases a history of head trauma was obtained; in the first it occurred about eight vears before the enlargement of the head was noticed; in the second only a short time previously. It is not improbable that these injuries were at least the predisposing cause of the bony proliferation.

The presence of tumor now in five cases of hemicraniosis with operation or necropsy, and probably also in the clinical case of Brissaud and Lereboullet, should make one fear that any pronounced local thickening of the cranium is likely to be associated with a tumor

6. Note in correcting the proof Oct. 31, 1907: During the past few months the swelling on the head dilectly in front of the opening in the skull increased markedly, and on Oct. 23,1907 , a convu]sion confined to the right upper limb and right side of the face occurred. It is not known whether the right lower limb was affected or not An operation was decided on. The swelling was well defined superficially, but was adherent to the bone. The bone beneath it was about one-half inch in thickness and softer than normal bone. It was easily cut with a knife, so that the outer portion was removed with the tumor. The latter was firm and fibrous in appearance. A large tumor was found beneath the dura. It was very soft, and was entirely removed with a spoon. The cavity was lined by the cerebral coltex the convolutions of which could be seen by the cerebral cortex, the convolutions of which could be seen from before backward. and 3 inches from above downward. The from before backward, and 3 inches from above downward. The
piece of dura from which the tumor had grown was found and removed. Microscopic examination showed the tumor to be an endo. thelioma. The operation was performed by Dr. C. H. Frazier. The patient made a rapid recovery, was not in danger at any time, had no symptoms of cerebral disease, and left the hospital ten days after the operation.

7. Monats. f. Ysych. u. Neurol., January, 1907, p. 87.

8. Berlin. klin. Wochschr., Dec. $17,1906$.

9. Berlin. klin. Wochschr., July 15, 1907, p. 875. 
growing from the dura, and operation should be attempted as soon as cerebral symptoms become manifest. It may be possible to remove the tumor in this way while it is yet small. Fortunately, this local thickening of bone is usually over or near the motor area of the brain, so that the symptom-complex is distinct, and the tumor growing from the dura is not likely to infiltrate the brain. Operations on these dural tumors are especially serious because of the severe hemorrhage, and they might be more successful if done in two stages.

The absence of all those symptoms which are frequently attributed to lesions of the left frontal lobe, in my second case after a large tumor had been removed from this lobe, is striking. The patient is a man engaged in a large and important business, and is as capable of performing his duties now as at any previous time. There is no failure of judgment, intelligence, power of attention, concentration of thought, memory, or of any of the intellectual functions. The tumor acted by pressure, not by infiltration.

To what are we to attribute the transitory aphasia, agraphia and hemiplegia following the second operation? Pressure on Broca's area explains the first very readily, but if we accept Marie's views we must assume that pressure was exerted on the lenticular nucleus, which was remote from the seat of operation. It is difficult to attribute the disturbance of speech and writing that developed shortly before the sccond operation to pressure on the lenticular nucleus, because the motor cortex or subcortical motor fibers were between the tumor and the lenticular nucleus, and the hemiparesis was not so intense as the speech and graphic disturbances, indicating that the centers or fibers of motion for the limbs were less implicated than those of speech and writing.

The first case is as follows:

CASE 1.-J. T., aged 47, male, came to my service at the Polyclinic Hospital in the beginning of 1899.

History.-His wife had not had any miscarriages or stillborn ehildren, and no history of venereal disease was ob. tained. He had taken iodids without benefit.

The following notes were read by me before the Section on General Medicine of the College of Physicians of Philadelphia. May, 1899, and the title of the paper appears in the Transactions of the College for that year, p. 191. It was my intention to publish promptly these notes in full in association with the very complete report of Dr. T. S. Kirkbride, Jr., which follow's, but the sad death of Dr. Kirkbride delayed the publication of them and made me lose interest in the case.

At the last meeting of the section (April, 1899) $\Upsilon$ presented a patient who was partially paralyzed on the right side of the body and had exostosis of the cranium. My object in doing this was to exhibit the man before operation was performed. The patient said that his right hemiparesis had developed after influenza; that he had been very much better until he had had another attack of influenza, when his paresis increased. I found later that his statements were not reliable, and that his memory was poor. His wife was not very intelligent and was not of much service in obtaining a correct clinical history. An intimate friend of the patient gave me the important details :

About sixteen years ago the man struck his forehead in descending a staircase. The severity of the blow can not be determined, but it was sufficient for the blow to be remembered after sixteen years. About eight years later the patient noticed that his head was becoming enlarged, and it is probable that the head had increased in size before the man's attention was called to it. About three or four years ago he began to have paresthesia in his right toes, and he examined these parts frequently in order to detect a sore of some kind, but none was found. The symptom was probably indicative of the beginning cortical lesion. At the same time his right leg began to grow weak, and after a zear or two he felt similar paresthesia and weakness in the right upper limb. A few months ago he had his first and only attack of eleptiform convulsions. His wife awoke and found him in general convulsions and unconscious. One day in the summer of 1898 he was aphasic for ten minutes. and was unable to say a word, but was entirely conscious. He had had similar attacks previously, less pronounced. This temporary aphasia was probably a sign of pressure affecting the speech area, and the convulsions were indicative of cortical irritation. He had not suffered to any extent from headache, nausea or vertigo. About a week before the operation, however, he began to have nausea and considerable headache.

Examination.- When he was presented at the last meeting of the section he was hemiparetic on the right side, but the face was not distinctly involved, objective sensation was intact, the patellar reflexes were exaggerated, especially that on the right side. The memory was poor, the station was good, the patient was partially aphasic. He knew the word he wished to say but was often unable to utter it, and was obliged to select other words than those which best expressed his meaning; to this extent he was paraphasic, but he had no true paraphasia, no jargon aphasia of the English writers. He did not mix the parts of speech without regard to the proper position of nouns and verbs; all he said was perfectly intelligible, and this is comprehensible from the fact that the necropsy showed that the speech area was only inrolved by pressure. The exostosis of the cranium was very striking. It began above the line of the hat brim on the left side in the area of the left temple, extended backward over the left Rolandic area and crossed the median line. The pupils were equal and the reaction to light and accommodation was good. Dr. Hansell reported that the man had bilateral optic neuritis going on to atrophy with limitation of the visual fields for form and color, and later he stated that the disease of the optic nerves appeared to be a chronic rather than an acute process.

Summary of Case.-In brief, the important features of the case were these: A blow on the head sixteen years ago; en largement of the left side and upper part of the skull extending over the left Rolandic area, first noticed by the patient about eight years ago; paresthesia and weakness in the right lower limb developing three or four years ago; a similar condition appearing in the right upper limb a year or two later; symptoms of aphasia, failure of memory, epileptiform con. vulsions, exaggerated patellar reflexes, bilateral optic neuritis of a chronic type, and later nausea and severe headache. The case seemed to me one entirely suitable for operation. Some disturbance of the sense of position in the right foot, the aphasic symptoms and the convulsions indicated a cortical lesion of some kind and the external bony enlargement sug. gested the possibility of a similar growth on the inside of the skull pressing on the leg center. for the cortical lesion eri. dently began in the leg center. The right-sided paresis was not complete paralysis, the intellect was not much impaired, and the general health was excellent. The symptoms were undoubtedly those of intracranial pressure.

In addressing the students of the Polyclinic Hospital before the operation was begun I said that we could not be positive that a bony growth would be found on the interior of the skull exactly similar to that on the outside, but that the existence of such a growth was quite possible and would explain the symptoms; that the most we could say was that the man had signs of focal intracranial pressure in the upper part of the left Rolandic area and that operation was demanded.

Operation.-Dr. Max J. Stern and Dr. John B. Rolerts examined the patient and an operation was performed, April 15, 1899 , by Dr. Stern, assisted by Dr. Roberts. A large bone flap was raised in the region of the thickened bone, but the hemorrhage was so profuse that the operation was stopped without any further attempt being made to remove the tumor, and the patient died about two hours later from loss of blood.

\section{AUTOPSY.}

The necropsy was performed by the late Dr. Kirkbride, and the following notes were read by him in May, 
1899. (Examination of head only. A complete autopsy was refused by the relatives of the patient.) :

The scalp of the vertex, on removal of the dressings covering the head, is seen to have been turned back at the operation in a large flap with the base posteriorly. The under surface of the flap is, in the left parietal region, considerably lacerated, evidently owing to the breaking up of firm adhesions between the pericranium and the bones of the skull. In the same region the tissues of the scalp are indurated, there being marked increase in the fibrous tissue between the bundles of which there are here and there small spicules of bone. The vault of the cranium has been removed at the operation in a large oval area about $0 \times 12 \mathrm{~cm}$. in size, with the center slightly to the left of the middle line. The portions of bone removed at the operation vary in size from 0.9 to $2.5 \mathrm{~cm}$; the largest is $10.5 \mathrm{~cm}$. long by $4 \mathrm{~cm}$, broad. On the outer surface of this piece there are irregular, partly nodular exostoses, some firm and closely adherent to the underlying bone, others honey-combed and friable. Shreds of pericranium adhered to the central portion of the outer surface of this fragment. The inner surface is in its central portion distinctly convex and is uneven, with shreds of dura still adhering. Where the dura has been torn away the bone has a honey-combed appearance. On sawing through the fragnent the cut surface shows an almost uniformly indurated hone, the location of the diploe appearing simply as an indistinct band of darker color and less firm consistence between the more compact outer and inner tables which are greatly thick. ened. The smaller fragments of excised bone resemble the one just described, but are in general thinner and with less evidence of adherent pericranium and dura. On the inner surface of one of these smaller pieces there is a nodular exostosis measur. ing $4 \times 6 \mathrm{~mm}$. and projecting $3 \mathrm{~mm}$. from the surface.

The remaining portion of the vault of the cranium removed at the autopsy presents no abnormalities, the impressiones digitatæe are not deep.

The dura is throughout somewhat more than normally ad. herent to the bone. It presents an uneven, lacerated appear. -ance in an irregular area measuring $5.5 \times 7.5 \mathrm{~cm}$. located over the upper left motor region and extending 1 to $2 \mathrm{~cm}$. beyond the middle line on the right (seat of operation). The mem. brane is here of a dark red color and appears much thickened In the surrounding portions of the dura there are scattered spots of bright red color (hemorrhage) and throughout the membrane is moderately thickened. Over the right hemisphere the dura is not adherent except along the central portion of the longitudinal fissure, and here it is easily detached. In the adherent portion are several small bony formations. The dura of the left hemisphere appears to be firmly adherent over a considerable area and is therefore left in place. On the surface of the dura about $3 \mathrm{~cm}$. in advance of the middle portion of the Rolandic fissure is a nodule of bone measuring $1 \mathrm{~cm}$. in length and $0.5 \mathrm{~cm}$. in width. The cerebral cortex is slightly depressed by this bony formation. On the left surface of the falx immediately below the collection of small bony growths mentioned in connection with the right hemisphere, there is a thin lamina of bone $1 \mathrm{~cm}$. long resting against the median surface of the left hemisphere. Directly posterior to this, also on the left surface of the falx, is a similar bony plate measuring about $2 \mathrm{~cm}$. in length and $1 \mathrm{~cm}$. in width. The longitudinal sinus is much narrowed where it is included in the region of thickened dura; it is patulous, however, and contains no thiombi. The removal of the brain shows the apices of the temporal lobes adherent to the dura; in the same region the impressiones digitatæ are unusually deep, otherwise the base of the skull is normal.

The brain and the posterior half of the left eye were removed and placed in 7 per cent. formol.

The brain preserved in formol: The right hemisphere, except for the adhesion of the dura already noted, appears normal. Over the left hemisphere there is an area of marked depression $4 \mathrm{~cm}$. in width and $3 \mathrm{~cm}$. anteroposteriorly, which in its posterior portion encroaches on the upper part of the Rolandic fissure and which extends on the right as far as to the longitudinal fissure. The dura appears in this area to be firmly adherent to the cerebral cortex. The portion of dura apparently adherent to the cortex is more extensive than the area of depression, measuring $7 \mathrm{~cm}$. anteroposteriorly by $5 \mathrm{~cm}$. laterally. Careful examination, however, proves that the apparent adhesion to the cortex is in reality the broad pedicle of a tumor arising from the dura itself and projecting far into the substance of the brain which has been pushed aside and compressed so as to form a deep socket in which the tumor lies. The pedicle measures $7 \mathrm{~cm}$. anteroposteriorly by $5 \mathrm{~cm}$. laterally. On turning back the dura the tumor is seen to project on the left fully $1 \mathrm{~cm}$. beyond the margin of the pedicle and it here appears as a convex grayish, firm gyrus-like mass beneath the pia mater; indeed, the resemblance to the neighboring convolutions was so marked that this portion of the tumor was at first mistaken for a convolution infiltrated by extensions of the tumor. Anteriorly and posteriorly the tumor projects but little beyond its attachment to the dura. On turning back the falx, a portion of the tumor covered only by the pia is visible on the median aspect of the hemisphere. This exposed surface of the tumor is irregularly semicircular in shape, measuring anteroposteriorly $4.5 \mathrm{~cm}$. and extending downward in its broadest part fully $2 \mathrm{~cm}$. below the circumference of the hemisphere. Everywhere at the margins of the socket in which the tumor lies the pia mater can be seen dipping down between the tumor and the cortex. (Figs. 1 and 2, page 2065.)

Position of the tumor: The fissure of Rolando. if not dis. torted, would in its upper portion pass through the center of the tumor. It occupies a little more than one-half of this fissure. The division of the left hemisphere in a frontal plane through the center of the tumor shows the latter to be much larger than appears from the surface. It is an oval mass, flattened on its upper surface. measuring $6 \mathrm{~cm}$. transversely, and projecting downward into the hemisphere fully $4 \mathrm{~cm}$. from the level of the dura. This measurement does not, however, represent the total encroachment on the brain substance, for, as already mentioned, the upper surface of the dura (i. e., of the tumor) is in this area concave, adapting itself to the convex inner surface of the greatly thickened skull. The socket of brain substance in which the tumor rests is lined by pia mater, beneath which a narrow band of gray matter indicates the position of the greatly compressed cortex which the tumor has evidently pushed before it in following by its growth the lines of least resistance. Beneath the center of the tumor, where the compression has evidently been most marked, the gray matter has almost entirely disappeared. On the median aspect of the tumor the compressed cortex tapers to a sharp elge, above which the tumor lies directly beneath the pia mater as already noted. 'The tumor itself appears on the cut surface of a grayish-white color. Its consistence is moderately soft except where in the upper central portion it contains bony particles. In this part the surface appears more compact and evenly granular. while below and at the margins projecting beyond the pedicle its formation is looser and more sponge-like. The surface is rather dry and mealy.

The uppermost part of the ascending parietal convolution appears to have been compressed by the tumor and is diminished in size. The second and third frontal convolutions are not involved and the area of Broca seems also to be intact. The median and middle portion of the left hemisphere is couvexed (on its median aspect) by the pressure of the tunor, while the median and middle portion of the right hemisphere is concave and adjusted to the convexity of the left. The gyrus fornicatus of the left hemisphere extends almost completely across the free surface of the corpus callosum. The posterior horn of the right ventricle is two or three times larger than that of the left. The aqueduct of Sylvius is very slightly enlarged. The right side of the optic chiasm is much flattened from below upward with the concavity on the lower surface. The left side is normal in shape. The right optic nerve near the chiasm is possibly one-fourth smaller than the left.

The following notes on the ocular findings are from Dr. E. A. Shumway:

The posterior portion of the left eye submitted for examination was embedded in celloidin and cut in sections parallel with its horizontal meridian. Transverse sections were also 
made through the optic nerve posterior to its entrance into the globe. The latter show very slight changes in this portion of the nerve, the intervaginal space being slightly dilated and the endothelial cells lining the processes of the arachnoid being in creased in number. The nerve fibers have retained their myelin sheaths and show no evidences of atrophy. The meridional sections show a swelling of the nerve head, within the lamina cribrosa, which reaches an elevation of $1.09 \mathrm{~mm}$. above the level of the chorioid. The retina at the optic nerve entrance is $\mathrm{dc}$ tached, somewhat folded, and is separated from the underlying chorioid by a layer of thickeried nerve fibers. The non-medullatod nerve fibers are swollen, show well-marked varicosities, and are separated from each other, evidently as the result of pre-existing edema. This condition of the fibers can be followed for some distance in the neighboring parts of the retina. There - is a moderate infiltration with cellular elements, which are assuming a spindle shape, and indicate the beginning of a con. nective tissue formation.

The retina is detached throughout the specimen, and the layer of rods and cones shows postmortem changes. The nerve fiber layer is thickened, edematous, and the fibers of Miuller show marked hypertrophy in places, producing irregular elevations on the outer surface of the membrane. No hemorrhage is present in either retina or nerve.

The chorioid is very densely pigmented. At a point $5 \mathrm{~mm}$. to the nasal side of the optic nerve entrance is a deeply pigmented growth, which measures $6 \mathrm{~mm}$, in its greatest vertical, and $4 \mathrm{~mm}$. in its greatest horizontal diameters, and $0.9 \mathrm{~mm}$. thick. It is composed largely of pigment cells which are evidently proliferated stroma cells, but shows also a large num. ber of non-pigmented and round spindle cells with large, deeply staining nuclei, closely packed between the chorioidal vessels. The growth has apparently sprung from the posterior layer of the chorioid, but the cells have infiltrated the anterior layers, containing the smaller capillaries. The pigment cells of the retina pass over its surface undisturbed, and the retina shows no evidence of inflammatory reaction. 'In the neighborhood of the growth the chorioidal vessels are widely distended, and both the vessels and the chorioidal stroma show a slight leucocytic infiltration. The growth is therefore to be diagnosed as a melanosarcoma of the chorioid.

Diagnosis: Papillitis with swelling of the nerve head $1 \mathrm{~mm}$. above the chorioidal level; moderate circumpapillary retinitis; beginning melanosarcoma of the chorioid.

This finding of a melanosarcoma of the chorioid by Dr. Shumway in association with an endothelioma of the cerebral dura is interesting.

CASE 2.-A. B., male, aged 42, was referred to me June 28, 1906 , by Dr. H. C. Westervelt, when the following notes were made. He had been under the care of Dr. J. I. Johnston.

Chief Complaint.-An enlargement in the left parietal region; right-sided weakness, staggering to some extent; some motor aphasia, with slow indistinct speech, possibly sensory aphasia.

History.-Six or seven months ago he observed a gradually increasing swelling in his cranium over and anterior to the left parietal region. This was accompanied by severe left-sided headache. Several weeks later he found himself unable to articulate correctly and stammered and mouthed his words in. distinctly when speaking. There was no weakness in the arms or legs, but he has felt numb in his right arm and leg, and occasionally staggers rather badly when walking. Otherwise there have been no sensory disturbances. His sight, so far as he knows, is good, but he can not read well, as gradually the lines appear to waver on the page. His memory is not nearly so good as it was; when speaking he has definitely in mind what he wants to say, but is slow in getting words to express himself, and then speaks hesitatingly and with ap. parently great effort. His voice, he believes, has grown weaker. He has no defect in hearing. About two months ago, he was at Mt. Clemens for five weeks, where he underwent treatment. After he returned, he had hypodermic injections of bichlorid of mercury followed by inunctions. With this treatment he thinks the tumor in his head lessened in size and that his speech and memory improved to some extent. But during the past four weeks he thinks they have grown worse again.
Examination.--His bowels are constipated, appetite is poor, tongue coated, and he has lost 15 pounds since January. He sleeps well. Occasionally there is some pain over the affected part of his head. No tremors or convulsive movements have occurred in face, arms, or legs. On admission to the hospital, temperature, pulse and respiration are normal. His wife says that in the beginning of the present disturbance he. staggered in walking like a drunken man, and at times (lasting 15 or 20 minutes) seemed utterly unable to speak. Physically, he is well developed, somewhat poorly nourished, flabby; with very moderate panniculus adiposus. On the left side of his cranium, extending forward from above and behind his left ear there is an extensive, gradual swelling, hard and not painful to touch, producing slight asymmetry of his head.

Eye examination by Dr. de Schweinitz, June 30, 1906: Pupillary reactions are normal. Extraocular muscles are normal. In extreme outward rotation on each side there is very slight oscillation of the eyeball of each cye. Fundus shows no evidence of optic neuritis. There is slight over-fullness of the retinal vessels. Color perception normal on both sides.

On looking at the ceiling the winkles in the right side of the forehead are not quite so distinct as those in the left. In closing the eyes the furrows about the right ‘ ye are not so deep as those about the left, but there is no weakness of the orbicularis palpebrarum. When the face is at rest the right corner of the mouth droops a little, and the right nasolabial fold is not quite so distinct. In showing his teeth the right nasolabial fold is not so deep as the left. Je can not draw up the right corner of the mouth separately nearly so well as the left. Speech is somewhat thick, and while he speaks without any great interruption, he has evidently at times difficulty in getting the word he wants. His memory is poor. There is no history of diplopia. The tongue deviates to the right when protruded. The extraocular muscles seem to be very good. Pupils are not quite equal, the right being a little larger than the left. In looking at a near object the pupil dilates in each eye; in looking into space the pupil of each eye at first contracts distinctly and then dilates. Reaction to light is prompt in each eye, as is also contraction in convergence. A little involuntary jerking occurs occasionally on the left side in the lower part of the face. (Dr. Jones says he has had this facial tic since he has known him, 23 years.)

The swelling above and in front of the left ear is very dis. tinct and large. He winces a little when the tumor is palpated. He has had a little vomiting at times, probably due to iodids. He has neither word blindness nor word deafness. Sensations for touch and pain are normal in both sides of the face.

The grasp of the right hand is fair, but not so good as that of the left. He has been a right-handed man, and he has noticed that the right hand has become a little weak. Sensations for touch and pain are normal in each hand. Stereognostic perception is normal in each hand. Biceps and triceps reflexes are distinct on each side, a little prompter on the right. Sense of position is normal in the fingers of each hand. Resistance to passive movement is a little weaker in the right upper limb. Patellar reflex is prompt on each side, and exaggerated a little on the right. Standing erect with eyes open he sways a little, and the sway is not distinctly increased by closing the eyes. The gait is very good with eyes open or closed. Slight indication of ankle clonus is detected on both sides, but no Babinski. Sensations for touch and pain are normal in each foot. Achilles jerk is prompt on each side, and about equal. He can not take solids because of bloody purging.

July 3, 1906: He was observed stumbling again to-day, as he did a few days ago. He is in a very excitable, state and is a little unstrung. He is now eager for operation to rid him of his symptoms. Speech is, if anything, more indistinct than before. Weakness in the right upper and lower limbs is not more marked, but he sometimes carries his right arm while waking, as if he were afraid of hurting it.

July 5, 1906: He was asked to write a letter, but after writing. a few words stopped and was not able to go on. He is getting very nerrous and has the greatest difficulty in articulating. 
July 7, 1906: Transferred to Dr. Frazier's service for operation.

Operation.-A section of bone comprising the outline of the tumor mass was removed by means of trephines and chisels. It was greatly thickened. The dura was found somewhat thickened, but was not opened, as the abnormal thickness of bone seemed to be sufficient to account for the symptoms. The man made an excellent recovery from the ether and was only slightly nauseated. Microscopic examination of the bone removed showed no appearance of tumor cells.

Subsequent History.-The patient made almost a complete recovery, attended to his business as formerly, and seemed well, but had some return of symptoms a few months later.

Sept. 4, 1906: He yawns much. The site of the operation is depressed and tender to touch. His right hand feels as though it were asleep and is numb. His speech is a little thicker than at his last examination, but he has no aphasia. The grasp of eacl hand is good. It requires a little effort for him to draw up the right corner of the mouth.

Oct. 23, 1906: His speech has become affected, is slow, and a little thick. He has much headache and is weaker than he was, but is not dizzy.

Nov. 10, 1906: 'l'he speech is much worse than it was ten days ago. He can say short sentences, but so soon as he at. tempts to tell anything, he becomes much confused and many words he can not speak. If he speaks slowly and is not excited he can make himself understood. He can not write correctly, as shown by the letters he attempts to write to his wife. $\mathrm{He}$ has had severe headache for the past fow mornings. The grasp of each hand is fair. $\mathrm{He}$ has had difficulty in walking downstairs during the past two or three weeks. Resistance to passive movements is good in the lower limbs. The patellar re. flex is exaggerated on each side, more so on the right side. The mental condition is good. It was evident that some lesion was developing at the site of the former operation, and fearing tumor, I referred the patient again to Dr. Frazier.

Second Operation.-An operation was performed by $\mathrm{Dr}$. Frazier November 17. The old skin flap was opened. Bleeding was very profuse. The dura was cut and a tumor was found in the center of the opening. It was shelled ont, although.in so loing the forward part, which extended beyond the original rpening, was broken, and was taken out in fragments. (Fig. 4.) Its position must have been above Broca's area and in front of the central fissure.

Result.-The patient was completely paralyzed on the right side and completely motor aphasic as a result of the operation. He began to recover the power of his right limbs within a few days, and within four or five days he had recovered almost as much power as he had before the operation, when he showerl slight hemiparesis. After a few days he could say "Yes," "No," and one or two other short words. Gradually he became able to add a few more words, and those he said were usually ristinct. On November 23 he was able to say a number of words in repeating after the examiner, and a few spontaneously, but he couid not put words together. He occasionally said two or three words with great difficulty. He was perfectly intelligent and not at all word deaf. He showed no intellectual defect. He could not write except that he managed to write, "Look at them." He read and obeyed five simple commands, when written, such as: "Put your right hand on your ear." He was not ataxic, and recognized words in the newspaper (Fig. 5):

Dec. 1, 1906: There is some weakness of the right muscles of mastication, the tongue deviates a little to the right, the right side of the face in the lower distribution is a little weak, Motor speech is still disturbed but is much better. He can say sentences and make himself understood, but many words he can not get and his sentences contain only a few words. The grasp of the right hand is hardly weaker than that of the left and is about normal. He picks up small objects with his right hand without difficulty. The sense of position and stereognostic perception are normal. The power in each lower limb is rormal. The patellar reflex is prompt on each side, a little more so on the right. Two or three days after the operation he was able to communicate with his wife by pointing to letters she showed him so as to spell words.
Dec. 18, 1906: The speech is greatly improved and only occasionally he has difficulty in getting a word, but his words are sometimes indistinct. His mentality has in no way been impaired. There is still a little weakness of the lower part of the right side of the face. He complains of some numbness of the right thumb and of the right upper lip and right gum. There is a little swelling over the seat of operation, but this is not distinctly painful. The grasp of the right hand is excellent. He has no disturbance of stereognostic perception in the right hand. Both patellar reflexes are prompt, the right more so.

the opening in the skull according to Anderson-Machin lines is $3 / 4$ inch behind and $21 / 4$ inches in front of the fissure of Rolando. The opening at its greatest width is 3 inches (Fig. 6).

Dr. de Schweinitz reported Dec. 19, 1906: "The slight edema of the nerve head, the so-called edematous optic neuritis, which I observed when last I saw the patient, has entirely disappeared and vision is absolutely normal. I made some suggestions in regard to a change in the use of his glasses, which I hope will be of service. There are no muscular anomalies, and the field of rision is normal."

Dr. de Schwcinitz' previous report, without date, but made after the patient had entered the hospital for the second operation, and probably just after the operation, to which he refers, is as follows: "V. 4/4. No diplopia; some nystagmus in outward rotation; slight but distinct optic neuritis, more in the right eye; veins very full ; temporal edges not yet involved."

.ran. 22, 1907: Speech is still thick, but the man savs all that he wishes to. Both patellar reflexes are a little prompter than normal. The tongue is protruded straight. The lower part of the right side of the face is a trifle weak. The grasp of each hand is excellent. He feels splendidly. The numbness in the right hand has disappeared except in the thumb. He has no headache and no vertigo. Stercognostic perception is normal. He says that a year and a half ago he received a severe blow against a beam at the region where the enlargement of the head occurred. This information was not obtained previously. He was nearly unconscious from this. If he speaks slowly he speaks distinctly.

March 28, 1907: He has been feeling so well he dicl not think it necessary to see me. Very slight weakness of right lower part of face may be detected. Grasp of the right hand is normal. The patellar reflex is about normal on each side. Gait is normal. A note from Dr. de Schweinitz of this date is as follows: "Vision is normal and there are no ophthalmoscopic lesions in the eye grounds; perhaps a little over-fulness of the retinal veins. Pupil reflex normal; no diplopia. No change in the right field; moderate concentric contraction of left field. Slight reduction of light sense $(6 / 10)$."

[This article is part of a symposicm. The discession Will appear with the other papers Later.]

Odorless Chamber Crematory.-In Hygirne Gén. et A ppliquée, September, Thierry and Brêchot give an illustrated description of what they call a "domestic incinerator" for destroying by fire all infectious material in the sick room, both fluids and solids, without the slightest odor in the room. It consists of a jar with a capacity for 10 liters above the grating and 5 liters of fluid below. The cover fits into a rim of sand, and the jar has an outer covering of asbestos. The patient uses the jar for stools if able to get up; if not, the bedpan is rinsed out each time before he uses it with half a glass of very soapy water, which prevents anything sticking to its inner surface. Two openings in the jar near the bottom and top are connected by pipes with a can of gasoline. To cremate the contents of the jar the cover is replaced by a covered gasoline burner. There is also a contrivance for a gasoline flame in the lower part of the jar. The burner cover ends through a large pipe carried into the fire place. The fluids are rapidly evaporated and the infectious material, dressings, stools and the sawdust (used as an absorbent) are speedily reduced to ashes, the entire process being complete in less than an hour when the jar is filled to its utmost capacity with 5 liters of fluid. The apparatus, they state, has proved satisfactory in every respect. 

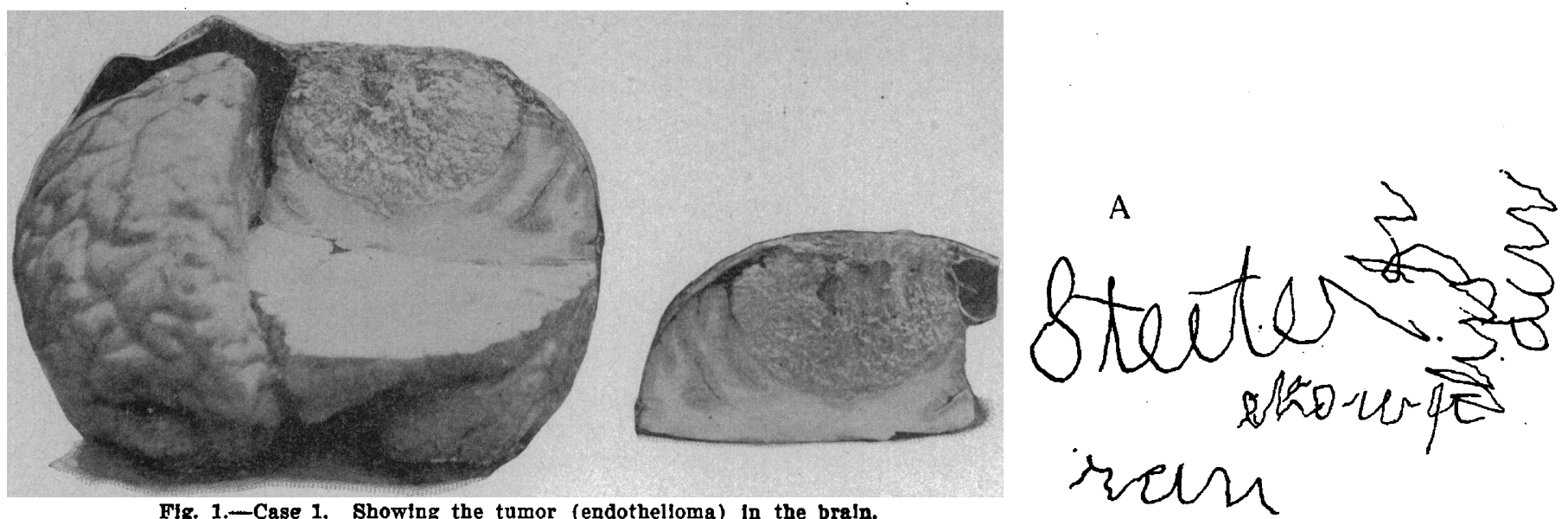

Fig. 1.-Case 1. Showing the tumor (endothelloma) in the braln.

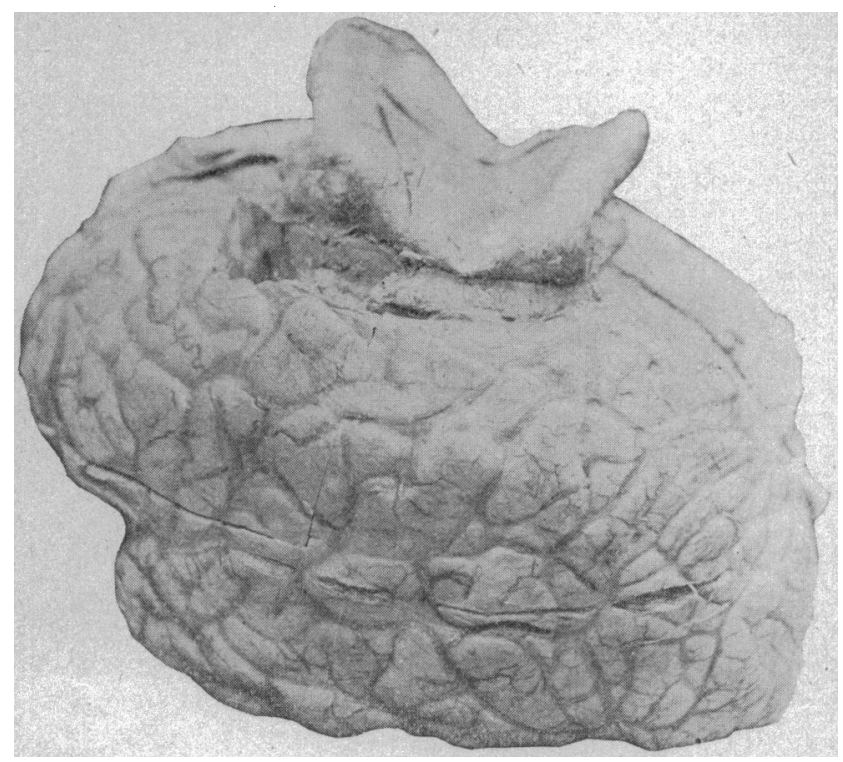

B Philaralphia $1 / 25 / 07$ B 3 cy spiller.

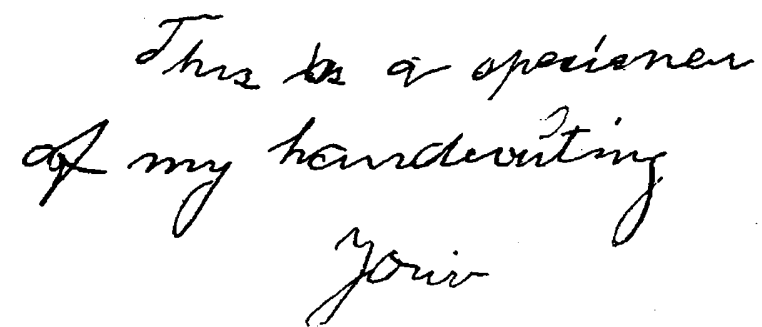

Fig. 5.-Case 2. $A$, writing done with the left hand 3 or 4 days after the second operation. The right hand could not be used in writing. $B$, writing on eighth day after the second operation.

Fig. 2.-Case 1. Showlng position of the tumor attached to the dura. Ar. Trm cy, Opunew, fenly 26 thi906

$$
\text { Leaw dorctin. }
$$

Kandall in a fur tays. deshak, thesefore, be abligel, if you mill timily wite to the loctor, an yow proposed

$$
\text { Boy tinly, }
$$

$B$ dete so hand for me to wuth, that Q Anow yow wid

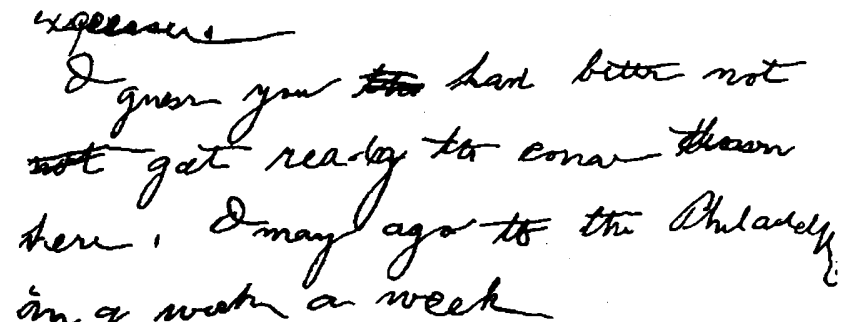
in a wath a week

Fig. 3.-Case 2. A, writing 19 days after the first operation. The man could not write at all for some time before the operation. B, writing 14 days before the second operation.

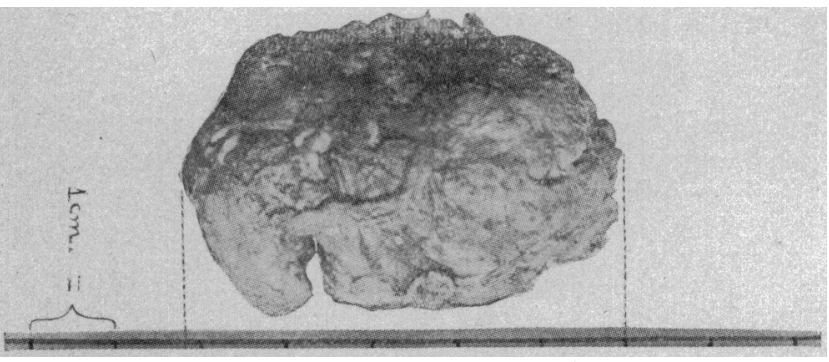

Fig. 4.-Case 2. Tumor removed.

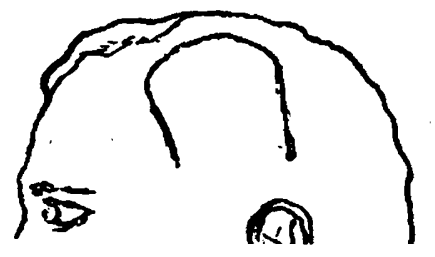

Fig. 6.-Case 2. Traclng of photograph showing the position of the bone flap.

Illustrating Artiche By Dr. Winliam G. Spmllfr. 